\title{
STRATEGI PEMASARAN PENDIDIKAN: ANALISIS FAKTOR DETERMINAN PEMASARAN PENDIDIKAN YANG MEMPENGARUHI MAHASISWA KULIAH DI STAIN BENGKALIS
}

\author{
Khairul Azan \\ Sekolah Tinggi Agama Islam Negeri (STAIN) Bengkalis \\ email: khairulazan18@gmail.com
}

\begin{abstract}
This quantitative study aims to describe education marketing conducted at STAIN Bengkalis and describe the determinants of educational marketing which are dominantly affecting students to study at STAIN Bengkealis by using survey method to collect the data. The subjects of this study were students spread into 14 Study Programs with a population of 1,590 people. To determine the number of samples, a proportional random sampling technique was applied and obtained a sample of 309 respondents. For the purpose of collecting the data, a questionnaire with three alternative answers (Likert scale) was distributed to the sample. Data analysis techniques used descriptive analysis with WMS (Weighted Means Scored) formula. The results showed that educational marketing at STAIN Bengkalis had gone well. This is evidenced by the acquisition of the overall average value which includes several indicators of educational marketing, namely products, costs, location, promotion, HR, physical buildings and processes of 2.27 in the high category. The most dominant educational marketing factor is the cost with an average value of 2.41 (bigh), and followed by product factors with an average value of 2.39 (high), HR factors with an average value of 2.32 (bigh), location factors with an average value of 2.30 (bigh), promotion factors with an average value of 2.28 (bigh), process factors with an average value of 2.13 (bigh), and physical building factors of 1.96 (enough).
\end{abstract}

Keywords: Educational Marketing, Students

\begin{abstract}
Abstrak: Penelitian ini bertujuan untuk mendeskripsikan pemasaran pendidikan yang dilakukan di STAIN Bengkalis dan mendeskripsikan faktor determinan pemasaran pendidikan apa saja yang dominan mempengaruhi mahasiswa untuk kuliah di STAIN Bengkalis. Pendekatan yang digunakan dalam penelitian ini adalah kuantitatif dengan metode survei. Adapun subjek penelitian adalah mahasiswa yang tersebar ke dalam 14 Program Studi dengan jumlah populasi 1.590 orang. Penentuan jumlah sampel dengan menggunakan teknik proporsional random sampling dan diperoleh sampel sebesar 309 responden. Pengumpulan data dalam penelitian ini menggunakan angket (skala likert). Teknik analisis data menggunakan analisis deskriptif dengan rumus WMS (Weighted Means Scored). Hasil penelitian menunjukkan bahwa pemasaran pendidikan di STAIN Bengkalis telah berjalan dengan baik. Hal ini dibuktikan dengan perolehan nilai rata-rata keseluruhan yang meliputi beberapa indikator pemasaran pendidikan yaitu produk, biaya, lokasi, promosi, SDM, bangunan fisik dan proses sebesar 2,27 dengan kategori tinggi. Faktor pemasaran pendidikan yang paling dominan yaitu biaya dengan nilai rata-rata sebesar 2,41 (tinggi), dan disusul oleh faktor produk dengan nilai rata-rata sebesar 2,39 (tinggi), faktor SDM dengan nilai rata-rata 2,32 (tinggi), faktor lokasi dengan nilai rata-rata 2,30 (tinggi), faktor promosi dengan nilai rata-rata 2,28 (tinggi), faktor proses dengan nilai rata-rata 2,13 (tinggi), dan faktor bangunan fisik sebesar 1,96 (cukup).
\end{abstract}

Kata kunci: Pemasaran Pendidikan, Mahasiswa 


\section{PENDAHULUAN}

Mahasiswa merupakan bagian yang tidak terpisahkan dari esksistensinya sebuah perguruan tinggi. Kehadiran mahasiswa bagi perguruan tinggi bagaikan sepasang sepatu yang ketika hilang salah satunya maka fungsi sepatu tidak akan ada artinya lagi. Mengingat begitu pentingnya mahasiswa bagi tumbuh kembangnya perguruan tinggi, maka hendaklah para pengelola memposisikan mahasiswa sebagai row input strategis yang harus diprioritaskan dalam pengembangan kampus kearah yang lebih maju. Pemahaman ini perlu dilakukan mengingat kompetitor dibidang pendidikan tinggi yang begitu banyak dengan latar belakang pendirian yang beragam serta tawaran produk yang sangat menjanjikan.

Agar itu bisa terwujud maka perguruan tinggi dituntut memiliki strategi yang ampuh bagaimana menjaring mahasiswa sebanyak-banyaknya lewat pemasaran pendidikan yang dilakukan. Secara definisi pemasaran pendidikan tediri dari dua kata yaitu pemasaran dan pendidikan. Pemasaran adalah memuaskan kebutuhan pelanggan. Bila pemasaran memahami kebutuhan pelanggan, maka ia dapat mengembangkan produk dan jasa yang menyediakan nilai unggul bagi pelanggan, menetapkan harga, mendistribusikan dan mempromosikan produk dan jasa itu secara efektif, sehingga produk dan jasa itu mudah dijual (Kotler dan Amstrong, 2008). Lebih lanjut, pemasaran juga diartikan sebagai satu fungsi organisasi dan seperangkat proses untuk menciptakan, mengkomunikasikan dan menyerahkan nilai kepada pelanggan dan mengelola hubungan pelanggan dengan cara yang menguntungkan organisai dan para pemilik sahamnya (Kotler dan Keller, 2007). Selain itu pemasaran juga dipahami sebagai suatu proses sosial dan manajerial yang di dalamnya individu dan kelompok mendapatkan apa yang mereka butuhkan dan inginkan dengan menciptakan, menawarkan, dan mempertukarkan produk yang bernilai dengan pihak lain (Ruslan, 2003).

Sedangkan pendidikan itu sendiri adalah usaha sadar dan terencana untuk mewujudkan suasana belajar dan proses pembelajaran agar peserta didik secara aktif mengembangkan potensi dirinya untuk memiliki kekuatan spiritual keagamaan, pengendalian diri, kepribadian, kecerdasan, akhlak mulia, serta keterampilan yang diperlukan dirinya, masyarakat, bangsa dan negara (Undang-Undang Sistem Pendidikan Nasional No. 20 Tahun 2003). Lebih lanjut menurut Ki Hajar Dewantara pendidikan sebagai daya upaya untuk memajukan budi pekerti, pikiran serta jasmani anak, agar dapat memajukan kesempurnaan hidup yaitu hidup dan menghidupkan anak yang selaras dengan alam dan masyarakatnya (Wahyudin, 2009).

Berdasarkan definisi di atas, dapat disimpulkan bahwa pemasaran pendidikan adalah usaha untuk memberikan pelayanan prima kepada pelanggan pendidikan dengan cara 
menetapkan standar biaya, menyediakan pembelajaran yang sesuai dengan kebutuhan serta mensosialisasikan produk pendidikan kepada masyarakat disekitarnya sebagai pelanggan sekaligus pengguna jasa pendidikan. Sebagaimana menurut Alma (2003) pemasaran jasa pendidikan diartikan sebagai suatu proses sosial dalam merencanakan, mengorganisasikan, mengarahkan dan mengawasi yang didalamnya terdapat individu, anggota-anggota dan lembaga pendidikan mendapatkan apa yang mereka butuhkan dan inginkan dengan menciptakan, menawarkan, dan mempertukarkan produk yang bernilai kepada masyarakat.

Produk pendidikan tidaklah sama dengan produk dalam dunia bisnis (Fisik). Produk pendidikan lebih cenderung bersifat jasa. Menurut Griffin (Lupiyoadi dan Hamdani, 2006) karakteristik jasa sebagai berikut: 1) Intangibility (Tidak berwujud), 2) Unstorability (Tidak dapat disimpan), 3) Customization (Kustomisasi). Sementara itu dalam pandangan Islam, menurut Hidayat dan Wijaya (2017) pemasaran pendidikan memiliki karakteristik diantaranya: 1) Ketuhanan (Rabbaniyah), 2) Etika (Akblaqiyyah), 3) Realistis (Al-Waqi"iyyab), dan 4) Humanistis (Al-Insaniyyah).

Adapun tujuan dari pemasaran pendidikan adalah untuk membantu lembaga pendidikan dalam hal ini perguruan tinggi untuk tetap eksis karena jumlah pelanggaan semakin meningkat. Hal ini terjadi karena perguruan tinggi mengetahui tentang apa yang dibutuhkan oleh pelanggannya sehingga bisa memberikan pelayanan yang maksimal tentunya akan berdampak pada kepuasan dari pelanggan pendidikan. Sebagaiman menurut Peter Drucker sebagai ahli dibidang manajemen mengatakan tujuan pemasaran adalah membuat agar tenaga penjualan menjadi berlebih dan mengetahui serta mamahami konsumen dengan baik sehingga pelayanan cocok dengan konsumen tersebut dan laku dengan sendirinya (Kotler, 1997). Senada dengan penjelasan tersebut Tim Dosen Administrasi Pendidikan UPI Bandung juga menyatakan secara rinci tujuan pemasaran pendidikan, diantaranya: (1) memberi informasi kepada masyarakat tentang produk-produk lembaga pendidikan, (2) meningkatkan minat dan ketertarikan masyarakat pada produk lembaga pendidikan, (3) membedakan produk lembaga pendidikan dengan lembaga pendidikan yang lain, (4) memberikan penilaian lebih pada masyarakat dengan produk yang ditawarkan, dan (5) menstabilkan eksisensi dan kebermaknaan lembaga pendidikan di masyarakat (Tim Dosen Administrasi Pendidikan UPI, 2009). Disamping itu dalam pandang Islam ativitas pemasaran merupakan sebuah proses bagaimana menawarkan sesuatu kepada orang lain sehingga orang tersebut mengetahui tentang apa yang kita jual. Proses penawaran tersebut hendaknya berangkat pada prinsip kepuasan pelanggan baik internal maupun eksternal, sebagaimana Allah Swt berfirman dalam Al-Qur'an Surat AnNisa ayat 29: 


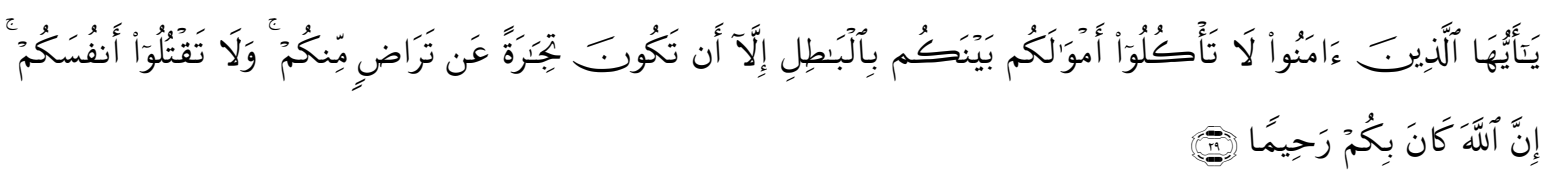

Artinya: "Hai orang-orang yang beriman, janganlah kamu saling memakan harta sesamu dengan jalan yang batil, kecuali dengan jalan perniagaan yang berlaku dengan suka sama suka di antara kamu. Dan janganlah kamu membunuh dirimu; sesungguhnya Allab adalab Maha Penyayang kepadamu."

Namun perlu digaris bawahi bahwa kemajuan sebuah perguruan tinggi tidak semertamerta begitu saja melainkan ada proses dan tahapan yang dilalui, dalam pandangan Islam pemasaran yang dilakukan oleh setiap institusi merujuk pada proses yang sistematis dalam memanfaatkan segala karunia Allah SWT. Proses sistematis tersebut dituangkan dalam perencanaan yang dilakukan untuk menjawab tuntutan dan kebutuhan masyarakat yang semakin dinamis. Perencanaan yang dibuat tentunya tidak terlepas dari pemberdayaan segala sumber daya yang Allah SWT telah sediakan dengan sebaik mungkin dalam rangka mendatangkan manfaat bagi orang banyak. Islam tidak melarang untuk berencana dan berbuat sesuatu yang lebih baik guna mendapatkan keuntungan, selagi apa yang dilakukan tidak mendatangkan pertentangan. Sebagaimana Allah SWT jelaskan dalam Al-Qur'an surat AlJumu 'ah ayat 10 yang artinya "Apabila telah ditunaikan sembabyang maka bertebaranlah kamu dimuka bumi, dan carilah karunia Allah dan ingatlah Allab banyak-banyak supaya kamu beruntung."

Makna "carilah karunia Allah" di atas menitik beratkan pada proses holistik dengan melibatkan orang lain dan cara yang beragam. Selagi usaha yang dilakukan itu halal maka lakukanlah. Di samping itu, makna penggalan kalimat di atas juga mengarah pada perencanaan strategis yang dibuat oleh masing-masing perguruan tinggi agar tetap bertahan. Perencanaan yang dibuat dijadikan sebagai arah agar masing-masing institusi berkembang dari waktu kewatu. Dimana perencanaan tersebut harus dijabarkan dalam rincian kegiatan yang ada dalam aktivitas pemasaran yang dilakukan. Berbicara perguruan tinggi adalah sesuatu yang hangat untuk dikaji mulai dari permasalahan dalam eksistensinya hingga kemajuan yang luar biasa diwujudkn oleh perguruan tinggi yang terbilang masih relatif muda, salah satunya adalah STAIN Bengkalis.

STAIN Bengkalis merupakan salah satu perguruan tinggi yang baru tumbuh dikawasan sumatra pada umumnya dan Riau khususya. STAIN Bengkalis merupakan satu-satunya Sekolah Tinggi Agama Islam Negeri di Provinsi Riau yang berlokasi di Kabupaten Bengkalis. Sebagai perguruan tinggi yang masih relatif baru tentunya akselerasi untuk kemajuan perlulah dilakukan. Saat ini STAIN Bengkalis telah memiliki 14 (empat belas) program studi yang mendapatkan persetujuan dari Menteri Agama setelah melewati evaluasi kelayakan akademik 
dan administratif oleh Ditjen Diktis Kemenag RI yang tersebar ke dalam tiga Jurusan yaitu Tarbiyah dan Keguruan, Syari'ah dan Ekonomi Islam, serta Dakwah dan Komunikasi Islam (Data kelembagaan STAIN Bengkalis).

Kemajuan yang diraih merupakan usaha yang luar biasa dilakukan oleh STAIN Bengkalis dalam menunjukkan eksistensinya sebagai perguruan tinggi yang layak diperhitungkan. Di samping itu, kemajuan STAIN Bengkalis saat ini juga ditandai dengan meningkatnya peminat dari calon mahasiswa untuk melanjutkan pendidikan ke STAIN Bengkalis yang dibuktikan dengan jumlah mahasiswa saat ini kurang lebih 2100 orang, dimana jika kita lihat itu adalah angka draktis pasca penegerian yang terbilang baru ditahun 2014.

Lebih lanjut besarnya peminat untuk kuliah ke STAIN Bengkalis juga dibuktikan dengan meningkatnya jumlah mahasiwa baru dari tahun ke tahun sebelum dan pasca penegerian. Pada tahun 2013 STAIN Bengkalis masih berstatus sebagai swasta, jumlah mahasiswa baru yang mendaftar pada tahun tersebut sebanyak 184 orang. Pada tahun 2014 jumlah mahasiswa baru meningkat sebanyak 198 orang dan ini adalah tahun pertama STAI berubah menjadi STAIN. Begitu juga pada tahun 2015 terus meningkat, jumlah mahasiswa baru sebanyak 364, pada tahun 2016 sebanyak 466 dan pada tahun 2017 sebanyak 750 orang (Data Bagian Akademik STAIN Bengkalis).

Berdasarkan data di atas, dapat dilihat bahwa jumlah mahasiswa baru yang masuk ke STAIN Bengkalis cenderung mengalami peningkatan yang luar biasa dari setiap tahunnya. Padahal STAIN Bengkalis secara geografis berada pada zona yang penduduknya tidaklah sepadat Ibu Kota Provinsi. Disamping itu, meskipun Kota Bengkalis hanyalah pulau kecil namun ada 4 (empat) perguruan tinggi di dalamnya yaitu Politeknik Negeri Bengkalis, Universitas Maritim, Akademi Komunitas Negeri Bengkalis dan STIE Syariah Bengkalis. Empat perguruan tinggi tersebut adalah bagian dari kompetitor internal (internal competitor) bagi STAIN Bengkalis. Sementara itu kompetitor eksternal (external competitor) adalah perguruan tinggi terkemuka yang ada di pusat Ibu Kota Provinsi seperti Universitas Riau (Unri), Universitas Islam Negeri Sultan Syarif Kasim Riau (UIN Suska Riau), Universitas Islam Riau (UIR) dan Universitas Lancang Kuning (UNILAK) serta kampus lain baik yang tersebar di Ibu Kota Provinsi maupun yang ada di Kabupaten-Kabupaten lain di Provinsi Riau.

Berdasarkan kemajuan yang diraih oleh STAIN Bengkalis tersebutlah maka penulis tertarik untuk meneliti lebih jauh lagi mengenai pemasaran pendidikan yang dilakukan merujuk kepada 7 (tujuh) bauran pemasaran menurut Ratnasari dan Aksa (2011), diantaranya: 1) Product (Produk), 2) Price (Biaya), 3) Place (Lokasi), 4) Promotion (Promosi), 5) People (SDM), 6) Physical Evidence (Bangunan fisik) dan 7) Process (Proses). Meskipun kompetitor begitu banyak namun 
tidak menghambat untuk STAIN Bengkalis tumbuh dan berkembang sesuai tuntutan masyarakat. Adapun rumusan masalah dalam penelitian ini yaitu: 1. Bagaimana pemasaran pendidikan di STAIN Bengkalis? 2. Faktor pemasaran pendidikan manakah yang dominan mempengaruhi mahasiswa untuk kuliah ke STAIN Bengkalis?

\section{METODE}

Penelitian ini menggunakan pendekatan kuantitatif dengan metode survei. Menurut Creswell (2010) "dalam rancangan survei, peneliti mendeskripsikan secara kuantitatif (angkaangka) kecendrungan-kecendrungan, perilaku-perilaku, atau opini-opini dari suatu populasi dengan meneliti sampel populasi tersebut. Dari sampel ini, peneliti melakukan generalisasi atau membuat klaim-klaim tentang populasi itu."

Penelitian ini dilakukan di STAIN Bengkalis. Objek penelitian ini adalah faktor-faktor determinan pemasaran pendidikan yang mempengaruhi mahasiswa kuliah di STAIN Bengkalis. Adapun subyek dalam penelitian ini adalah seluruh mahasiswa aktif yang tersebar dalam 14 Program Studi dengan total populasi 1.590 orang.

Untuk menentukan jumlah sampel, penelitian ini menggunakan teknik proporsional random sampling. Dari pengolahan data yang dilakukan diperoleh jumlah sampel sebesar 309 responden. Pengumpulan data dalam penelitian ini menggunakan angket yang berisikan pernyataan-pernyataan dengan tiga alternatif jawaban (skala likert).

Penelitian ini menggunakan analisis deskriptif. Analisis deskriptif bertujuan untuk menggambarkan rata-rata kecendrungan jawaban responden untuk masing-masing indikator. Analisis data deskriptif dilakukan untuk mengetahui penafsiran skor tertinggi dan terendah untuk setiap indikator. Untuk menganalisis data deskriptif, peneliti menggunakan teknik WMS (Weighted Means Scored) dari Furqon (2011).

\section{HASIL DAN PEMBAHASAN}

Hasil analisis deskriptif menunjukkan bahwa secara umum pemasaran pendidikan di STAIN Bengkalis telah berjalan dengan baik, ini dibuktikan dengan perolehan nilai rata-rata keseluruhan sebesar 2,27 dengan kategori tinggi yang tersebar ke dalam 7 (tujuh) indikator pemasaran. Untuk masing-masing indikator diperoleh nilai rata-rata sebesar 2,39 untuk indikator produk dengan kategori tinggi, 2,41 untuk indikator biaya dengan kategori tinggi, 2,30 untuk indikator lokasi dengan kategori tinggi, 2,28 untuk indikator promosi dengan 
kategori tinggi, 2,32 untuk indikator SDM dengan kategori tinggi, dan 1,96 untuk indikator bangunan fisik dengan kategori cukup, dan 2,13 untuk indikator proses dengan kategori tinggi.

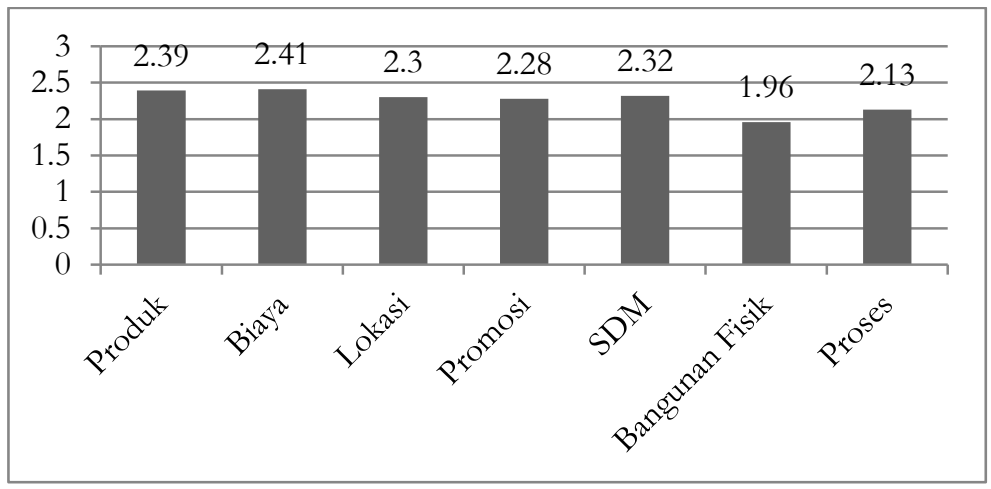

Gambar 1. Nilai Rata-rata Untuk Masing-masing Indikator Pemasaran Pendidikan di STAIN Bengkalis

Perolehan nilai rata-rata keseluruhan dengan kategori tinggi tersebut bermakna bahwa sebuah kewajaran bagi STAIN Bengkalis jika tahun ke tahun jumlah mahasiswa baru mengalami peningkatan disebabkan strategi pemasaran yang mulai diperhatikan. Hal ini sejalan dengan pendapat Yazid (2003) yang mengatakan bahwa bauran pemasaran terdiri dari semua variabel yang bisa dikontrol perusahaan dalam komunikasinya dengan dan akan dipakai untuk memuaskan konsumen sasaran. Bauran pemasaran yang dimaksud yaitu: produk, harga, distribusi, promosi, orang, bukti langsung, dan proses. Hal senada juga diungkapkan Payne bahwa produk jasa, harga ketersediaan jasa dan lokasi (tempat) jasa, promosi, orang, proses, layanan pelanggan dapat dimanfaatkan, untuk memuaskan konsumen, dalam hal ini calon mahasiswa (Payne, 2001). Dengan demikian dapat dipahami bahwa apabila 7 (tujuh) bauran pemasaran di atas dilaksanakan dengan baik maka akan berpengaruh pada terciptakan kepuasan dari konsumen dalam arti lain mahasiswa. Ketika konsumen telah merasa puas maka akan berdampak pada tumbuhkan kepercayaan mahasiswa untuk melanjutkan pendidikan di perguruan tinggi yang dimaksud.

Selanjutnya jika kita lihat pada masing-masing indikator nilai rata-rata tertingi terdapat pada faktor biaya. Biaya menjadi faktor utama mengapa STAIN Bengkalis menjadi salah pilihan yang diperhitungkan oleh calon mahasiswa baru untuk melanjutkan pendidikan di jenjang pendidikan tinggi. Biaya pendidikan yang dimaksud diantaranya biaya kuliah yang terjangkau, beasiswa yang beragam dan sistem pembayaran uang kuliah. Hal ini sejalan dengan pendapat Lupioyadi dan Hamdani (2006), bahwa keputusan penetapan harga juga sedemikian penting dalam menentukan seberapa jauh pelayanan layanan jasa dinilai oleh konsumen dan 
juga dalam proses membangun citra. Setelah faktor biaya barulah faktor produk menjadi pertimbangan bagi para mahasiswa. Produk disini meliputi prestasi perguruan tinggi, kredibilitas, ragam program studi yang ditawarkan serta prospek pekerjaan. Setelah itu dilanjutkan pada faktor SDM, lokasi, promosi, proses (pembelajaran dan layanan administrasi) dan bangunan fisik. Bangunan fisik memperoleh nilai rata-rata terendah diantara 7 (tujuh) bauran pemasaran pendidikan di STAIN Bengkalis. Rendahnya nilai rata-rata tersebut disadari memang STAIN Bengkalis belum memiliki bagunan fisik yang memadai baik dari desain gedung hingga fasilitas di dalamnya yang memberikan kesan tersendiri bagi para mahasiswa.

Adapun faktor determinan pemasaran pendidikan yang mempengaruhi mahasiswa kuliah di STAIN Bengkalis dilihat pada masing-masing prodi beragam, diantaranya sebagai berikut:

Tabel 1. Nilai Setiap Indikator Pemasaran Pada Masing-masing Program Studi

\begin{tabular}{|c|c|c|c|c|c|c|c|c|}
\hline \multirow[b]{2}{*}{ No. } & \multirow[b]{2}{*}{ Program Studi } & \multicolumn{7}{|c|}{ Indikator Pemasaran Pendidikan } \\
\hline & & Produk & Biaya & Lokasi & Promosi & SDM & $\begin{array}{l}\text { Bangunan } \\
\text { Fisik }\end{array}$ & Proses \\
\hline 1 & Pendidikan Agama Islam & 2,41 & 2,39 & 2,37 & 2,19 & 2,29 & 1,92 & 2,23 \\
\hline 2 & Tadris Bahasa Inggris & 2,23 & 2,47 & 2,16 & 2,19 & 2,29 & 1,92 & 2,04 \\
\hline 3 & $\begin{array}{ll}\text { Manajemen } & \text { Pendidikan } \\
\text { Islam } & \end{array}$ & 2,92 & 2,42 & 2,31 & 2,22 & 2,24 & 1,68 & 1,92 \\
\hline 4 & $\begin{array}{lll}\text { Pendidikan } & \text { Islam } & \text { Anak } \\
\text { Usia Dini } & & \\
\end{array}$ & 2,34 & 2,37 & 2,19 & 2,09 & 1,87 & 1,56 & 1,89 \\
\hline 5 & Pendidikan Bahasa Arab & 2,3 & 2,62 & 2,83 & 2,33 & 3 & 2 & 2 \\
\hline 6 & Ekonomi Syariah & 2,5 & 2,48 & 2,23 & 2,43 & 2,46 & 2,24 & 2,3 \\
\hline 7 & Siyasah Syariah & 2,37 & 2,47 & 2,35 & 2,28 & 2,39 & 2 & 2,12 \\
\hline 8 & Perbangkan Syariah & 2,43 & 2,33 & 2 & 2,58 & 2,44 & 1,94 & 2,16 \\
\hline 9 & Akuntansi Syariah & 2,4 & 2,32 & 2,26 & 2,16 & 2,5 & 2,16 & 2,35 \\
\hline 10 & Akhwal Syahsiyyah & 2,2 & 2,33 & 2,11 & 2,5 & 2,55 & 1,77 & 2,16 \\
\hline 11 & $\begin{array}{l}\text { Manajeme Keuangan } \\
\text { Syariah }\end{array}$ & 2,33 & 1,95 & 1,94 & 2,22 & 2,33 & 1,88 & 2,2 \\
\hline 12 & Manajemen Dakwah & 2,37 & 2,39 & 2,38 & 2,26 & 2,23 & 1,95 & 2,14 \\
\hline 13 & $\begin{array}{ll}\text { Komunikasi } & \text { Penyiaran } \\
\text { Islam } & \\
\end{array}$ & 3 & 2,5 & 1,66 & 2,16 & 3 & 1,66 & 2 \\
\hline 14 & Sosiologi Agama & 2,15 & 2,06 & 2 & 2,12 & 2,33 & 2,25 & 2,18 \\
\hline
\end{tabular}

\section{PENUTUP}

Berdasarkan hasil penelitian dan pembahasan di atas dapat disimpulkan bahwa:

1. Pemasaran pendidikan di STAIN Bengkalis telah berjalan dengan baik. Hal ini dibuktikan dengan perolehan nilai rata-rata keseluruhan yang meliputi beberapa indikator pemasaran pendidikan yaitu produk, biaya, lokasi, promosi, SDM, bangunan fisik dan proses sebesar 2,27 dengan kategori tinggi. 
2. Faktor pemasaran pendidikan yang paling dominan yaitu biaya dengan nilai rata-rata sebesar 2,41 (tinggi), dan disusul oleh faktor produk dengan nilai rata-rata sebesar 2,39 (tinggi), faktor SDM dengan nilai rata-rata 2,32 (tinggi), faktor lokasi dengan nilai ratarata 2,30 (tinggi), faktor promosi dengan nilai rata-rata 2,28 (tinggi), faktor proses dengan nilai rata-rata 2,13 (tinggi), dan faktor bangunan fisik sebesar 1,96 (cukup).

\section{REFERENSI}

Andrian Payne. (2001). The Essence Of Service Marketing. Diterjemahkan oleh : Fandy Tjiptono, Edisi Pertama. Yogyakarta: Penerbit Andi.

Buchari Alma. (2010). Pemasaran Stratejik Jasa Pendidikan. Bandung: Alfabeta.

Creswell, Research Design: Pendekatan Kualitatif, Kuantitatif, dan Mixed. (Terjemahan). Yogyakarta: Pustaka Pelajar.

Din Wahyudin, et al. (2009). Pengantar Pendidikan, cet.17. Jakarta: Universitas Terbuka.

Furqon. (2011). Statistik Terapan untuk Penelitian. Bandung: Alfabeta.

Philip Kotler \& Gary Amstrong. (2008). Prinsip-prinsip Pemasaran, Jilid 1 (Terjemah). Jakarta: Erlangga.

Philip Kotler \& Kevin Lane Keller. (2007). Manajemen Pemasaran Edisi Kedua Belas Jilid 1. Indonesia: PT Macanan Jaya Cemerlang.

Philip Kotler. (1997). Manajemen Pemasaran. Jakarta: PT. Prenhallindo.

Rahmat Hidayat \& Candra Wijaya. (2017). Ayat-ayat Al-Qur'an Tentang Manajemen Pendidikan Islam. Medan: Lembaga Peduli Pengembangan Pendidikan Indonesia (LPPPI).

Rambat Lupiyoadi \& A. Hamdani. (2006). Manajemen Pemasaran Jasa. Jakarta: Salemba Empat.

Ririn Tri Ratnasari \& Mastuti Aksa. (2011). Teori dan Kasus Manajemen Pemasaran Jasa. Bogor: Ghalia Indonesia.

Rusadi Ruslan. (2003). Manajemen Publik Relation Media Komunikasi, Konsep dan Aplikasi. Jakarta: PT. Raja Grafindo Persada.

Sujadi, E. (2017). Penerapan Pendidikan Karakter Cerdas Format Kelompok Untuk Meningkatkan Nilai Kejujuran Mahasiswa Bimbingan Konseling Islam (BKI) Institut Agama Islam Negeri (IAIN) Kerinci. Tarbawi : Jurnal Ilmu Pendidikan, 13(1), 97-108

Tim Dosen Administrasi Pendidikan UPI. (2009). Manajemen Pendidikan. Bandung: Alfabeta. 
Khairul Azan

Yazid. (2003). Pemasaran Jasa : Konsep dan Implementasi, Edisi Kedua. Yogyakarta: Penerbit Ekonisia Fakultas Ekonomi UII. 